\title{
Spor Bilimleri Alanı Akademisyenlerinin E-Spora Bakış Açılarının İncelenmesi ${ }^{1}$
}

DOI: $10.26466 /$ opus. 835215

\author{
$\underline{\text { Sibel Arslan }}^{*}$ - Mehmet Satılmış Bulut** \\ * Doç. Dr., Kırıkkale Üniversitesi, Spor Bilimleri Fakültesi, Kırıkkale/Türkiye \\ E-Posta: sblarslan06@gmail.com \\ ORCID: $\underline{0000-0002-4393-7528}$ \\ ** Polis Memuru, Yüksekova İlçe Emniyet Müdürlüğü, Hakkari/Türkiye \\ E-Posta: msbulut89@gmail.com \\ ORCID: $0000-0002-7987-3300$
}

Öz

Elektronik ortamlara erişimin hızla yaygınlaşması ve bilgisayar oyunlarına olan ilginin artması nedeniyle E-Spor hızla artan bir ilgiye sahip olmuştur. Bu ilginin bütün dünyada olduğu gibi Türkiye'de de arttı̆̆̆ bilinmektedir. Spor bilimleri alanında görev yapan akademisyenlerin E-Spora bakış açılarının incelenmesini amaçlayan bu araştırma, tarama modelinde betimsel bir araştırmadır. Araştırma evrenini Türkiye'de Spor Bilimleri alanında görev yapan akademisyenler oluşturmaktadır. Araştırmanın örneklemini 241 akademisyen oluşturmaktadır. Verilerin toplanmasında araştırmacılar tarafindan geliştirilen anket kullanılmıştır. Betimsel verilerin analizinde yüzde (\%), frekans $(f)$ ve aritmetik ortalama $(X)$ değerlerinden yararlanılmış; iki ayrı kümenin verdiği cevapların analizinde t-testi, çoklu grup karşılaştırmalarında Anova (tek yönlü varyans analizi) testi, farklılık yaratan grupları belirlemek amacıyla Tukey HSD Çoklu Karşılaştırma ve LSD Çoklu Karşılaştırma Testi kullanılmıştır. Araştırma sonucunda Spor Bilimleri akademisyenlerinin, E-Spora ilişkin görüşlerinin olumsuz olduğu ve spor olarak kabul etmedikleri belirlenmiştir. Ayrica akademisyenlerin E-Spora yönelik görüşleri ile cinsiyet, yaş, görev yaptıkları bölüm, elektronik oyun oynama durumları ve spor yapma sıklıkları arasında anlamlı farklılaşma olduğu belirlenmiştir.

Anahtar Kelimeler: elekronik spor, e-spor, bilgisayar oyunu, akademisyen, spor bilimleri.

\footnotetext{
${ }^{1}$ Kırıkkale Üniversitesi Sağlık Bilimleri Enstitüsü Beden Eğitimi ve Spor ABD’nda aynı başlıkla kabul edilen yüksek lisans tezinden üretilmiştir.
} 


\title{
Examining the Perspectives of Sports Science Academics on Electronic Sports
}

\begin{abstract}
Due to the rapid spread of access to electronic media and the increased interest in computer games, elektronic sport has gained an increasing interest. This interest is increasing all over the world as well as in Turkey. This research is a descriptive study which aims to examine the perspectives of academicians working in the field of sport sciences to electronic sports. Target population of the study are academicians which is working in the field of sport sciences in Turkey. The research sample consist of 241 academicians. A survey that is prepared by the researcher was conducted with representative group. The datas obtained within the research is analyzed with SPSS 20 programme. In the analysis of gathered datas, it is benefited from percent (\%), frequency ( $f$ ) and arithmetic mean (X) values and then the obtained results are interpreted. For the answers given by two groups $t$-test was employed, and for multiple group comparison Anova, to identify the groups that cause difference Tukey HSD Multiple Comparison and LSD Multiple Comparison Tests are used. As a result of the research, it was determined that the opinions of Sport Sciences academics about E-Spor were negative and they did not consider it as sports. Besides, it has been determined that there is a significant difference between the views of the academicians on E-Spor and the gender, age, department they work, electronic game playing situations and frequency of doing sports.
\end{abstract}

Keywords: electronic sports, e-sport, academician, computer game. 


\section{Giriş}

İlk çağlarda, insanların etraflarında gördüklerini taklit ederek ve yaptıklarını hareketlerle birbirlerine anlatarak farkında olmadan ortaya çıkarttıkları oyun (Uysal, 2005, s.1-2), teknolojik gelişmelerle beraber günümüzde yeni bir boyut kazanarak dijital ortama giriş yapmıştır. $\mathrm{Bu}$ oyunlar video, bilgisayar, elektronik ya da dijital oyunlar olarak adlandırılsa da hepsi benzer veya ortak özellikler taşır (Kirriemuir, 2005, s.25). Teknolojinin getirisi olan yeni oyunlarla beraber insanlar, gerçek hayatta yapamayacakları şeyleri sanal bir ortamda veya kişinin bireysel zevkleri doğrultusunda yapabilmektedir (Yoncac1, 2003, s.8).

İnsanlığın tarihini değiştiren teknolojik gelişmeler nasıl ki her alanda beden gücüne gereksinimi azaltmışsa, teknoloji çağının oyunları da bu durumdan nasiplenmiş, geleneksel sokak oyunlarının yerini sanal oyunlar almıştır. Bu doğrultuda "kurallı oyun" diyebileceğimiz spor da teknolojik gelişmelerden etkilenmiş ve gerçek sporlardan çok daha farklı özellikler taşıyan sanal bir oyun dünyası ortaya çıkmıştır. Bu sanal oyun dünyasının ortaya çıkarttı̆̆ yeni "kurallı oyun" türü “Elektronik Spor (E-Spor/eSpor/Espor)" kavramıdır.

Bazı çevreler E-Sporun, internet aracilığı ile dünyanın her yerindeki insanların sanal ortamda bir araya gelerek oyun oynayabileceği veya farklı ülkelerden gelen insanların buluşup belli bir mekanda ya da yine sanal ortamda oyun oynayabilecekleri, hem fiziksel hem de zihinsel uğraş gerektiren bir spor olduğunu kabul etmektedir (Argan, Özer ve Akın, 2006, s.2-3).

E-Sporun kurucu ülkesi Güney Kore olarak kabul edilmektedir ve bir spor dalı olarak görülmesi, bu ülkenin ev sahipliğinde 46 üye ülkenin bir araya gelerek 2008 yılında Uluslararası E-Spor Federasyonu'nun (International e-Sports Federation - IeSF) kurulması ile olmuştur (IeSF, 2017). Uluslararası Herkes İçin Spor Birliği (TAFISA) üyesi olan federasyon 2016 yılında uluslararası Olimpiyat Komitesine başvuruda bulunmuştur (IeSF, 2016). "Ulusal Olimpiyat Komiteleri" tarafından tanınan E-Spor, 2022'de Çin'de Hangzhou şehrinde yapılacak olan Asya Oyunlarında resmi bir spor dalı olarak yarışmalara kabul edilmiştir (Olympic Council of Asia [Ocasia], 2017). E-Spor dünyanın birçok ülkesinde resmi bir spor olarak kabul görmektedir (Jonasson ve Thiborg, 2010, s.292). Türkiye'de 2011 yılında kurulan Türkiye Dijital Oyunlar Federasyonu (TÜDOF), 2013 yılında 
Gelişmekte Olan Spor Branşları Federasyonu bünyesine katılmış; 2018 yılında ise Gençlik ve Spor Bakanlığına bağlı spor federasyonu statüsünde Türkiye E-Spor Federasyonu (TESFED) kurulmuş olup, E-Spor oyuncuları resmi olarak sporcu lisansı almaktadır. Türkiye E-Spor dalında federasyonlaşma yolunda harekete geçen ilk üç ülkeden birisi olmuştur (TESFED, 2019, s.3).

İnal'a (2000) göre spor, bireyin belli kurallara uygun olarak fiziksel aktivitesini, motorik becerilerini, zihinsel, ruhsal ve sosyal davranışların geliştiren ve bu yeteneklerini belli kurallara uygun olarak yarıştırmasını amaçlayan biyolojik, pedagojik ve sosyal bir uğraş alanıdır.

Ancak bir spor alanı olarak kabul görmeye başlayan, federasyonları kurulan hatta uluslararası önemli spor organizasyonlarında yer alması gerektiği tartışılan E-Spor, gerçek sporun barındırması gereken bu nitelikleri taşımaktan uzaktır.

Gerçek anlamdaki spor ile E-Spor arasındaki en önemli benzerlik ve elektronik oyunların spor olarak kabul edilmesi gerektiği yönündeki görüşlerin dayanak noktası, E-Sporun da fiziksel ve düşünsel çaba gerektiriyor oluşudur (Argan ve Akın, 2007, s.64). Türkiye E-Spor Federasyonu Başkanı Alper Afşin Özdemir, güncel E-Spor konularına dair yapmış olduğu bir röportajda "Bugün zaten sporu tanımladığımızda da fiziksel veya mental bir çabanın kompozisyonu, şimdi burada baktı̆̆ımızda fiziksel olarak inanılmaz bir emekten bahsetmiyoruz tabi ki ama satranç çok güzel bir örnek bu duruma, burada fazlasıyla zihinsel ve mental olarak çok ciddi bir çaba gerektiriyor. Burada takım oyunu da var, işte hamleleri ön görme de var, takım halinde strateji geliştirme de var bence bu yüzden çok doğal olarak bunun spor olarak adlandırılması lazımdı ki adlandırıldı" demiştir (Soysal, 2020).

Ancak iki kavram arasında göz ardı edilemeyecek farklılıklar söz konusudur. Sporda tüm faaliyetler "gerçek dünyada" gerçekleşirken, ESporda bütün faaliyetler "sanal dünyada" gerçekleşmektedir. E-Sporcular gerçek dünyada insan girdileri ve bilgisayar çıtılarını içeren spor ekipmanları kullanır ve oyun alanları sanal ortamlardır. Gerçek sporcular ise fiziksel nesneleri kullanırlar ve müsabaka alanları gerçek dünyadır (Hamari ve Sjöblom, 2017). E-Sporda klavye, mouse, kulaklık, internet vb. araç ve gereçler kullanilırken, gerçek sporlarda daha çok branşa özgü araç ve gereçler 
kullanılmaktadır. Spor fiziksel ve mental çabayı ön plana çikarırken, E-Spor daha çok mental çabayı ön plana çıkarmaktadır (Akın, 2008, s.45-46).

E-Spor, spordan beklenen yararların aksine durumlar oluşturmaktadır. Eletronik/dijital oyunların, dolayısıyla aynı statüde yer alan E-Sporun olumsuz etkilerinden başlıcaları "dil gelişiminde aksamalara ve gelişim geriliğine sebep olması, zaman israfina ve erteleme davranışının yerleşmesine sebep olması, duygu kontrollerinde zorluk yaşama ve kişilik bozuklukları, asosyalleşme ve aile içi iletişimi azaltması, sanal ile gerçeklik arasındaki farkı ayırt etmede güçlük, şiddet unsurları içerebilmesi nedeniyle saldırgan duygu, düşünce ve davranışların gelişmesine sebep olması, ders çalışma, kitap okuma ve fiziksel aktivitelere katılma zamanlarını azaltması sebebiyle akademik ve kişisel başarıyı olumsuz etkilemesi, bağımlılık, obezite, karpal tünel sendromu, dikkat bozukluğu gibi sağllk problemlerine sebep olması, kötü dil gelişimi ve çocukların çevrim içi tehditlere açık hale gelmesi" olarak gösterilebilir (Bilgi Teknolojileri ve İletişim Kurumu, 2017, s.7-8).

E-Sporun büyük bir hızla yayılmasının, yukarıda bahsedilen sorunları da daha geniş çevrelerde aynı hızla artıracağı ortadadır. Yukarıda bahsedilen zararlar sporun fiziksel, zihinsel, psikolojik ve sosyal yarar sağlama potansiyeli ve amaciyla ters düşmekte ve E-Spor hiçbir şekilde sporun sağladığı faydaları karşılamamaktadır. Buna rağmen oyun şirketlerinin teşvikleriyle E-Sporun popülerliği artmış, yatırımcilar ve sponsorlar bu alana yönelmiş ve E-Spor endüstrisi ticari bir sektör olarak büyümeye başlamıştır. E-Spor, bir spor branşı olmaktan çok ekonomik kazanç sağlayan bir alan olarak görülmelidir.

Elektronik oyunların "spor" olarak sunulmasının, bu oyunlara karşı oluşan antipatinin ve karşı çıkışların önünde koruyucu bir kalkan yaratma çabası olduğu düşünülmektedir. Spor kavramına karşı oluşmuş olan pozitif bakış açısı, ilerleyen zamanlarda ciddi sorunlara neden olacağı ortada olan E-Sporun yaygınlaşması için gizli bir örtü olarak kullanılmaya çalışılmaktadir.

Spor Bilimleri akademisyenleri, sporun yaygınlaşmasına ve gelişmesine gönül vermiş insanlar olarak, sporun mihenk taşlarıdır ve bu konu ile ilgili görüşleri önemlidir. Yapılan alan taramasında bu konu ile ilgili Spor Bilimleri akademisyenlerinin E-Spor ile ilgili görüşlerini yansıtan herhangi bir çalışmaya rastlanmamıştır. 
Bu araştırmanın genel amacı Spor Bilimleri alanında görev yapan akademisyenlerin E-Spor hakkındaki düşüncelerinin belirlenmesidir.

\section{Yöntem}

Halen Spor Bilimleri alanında görev yapan akademisyenlerin E-Spor bakış açlarını tespit etmek için yapılan bu çalışma, tarama modelinde, betimsel bir araştırmadır.

Araştırmanın evrenini 2019 yılında Türkiye'de Spor Bilimleri alanında görev yapan 1085 akademisyen oluşturmaktadır. Elektronik ortama aktarılan anket akademisyenlerin e-posta adreslerine gönderilmiş ve dönüş yapan 241 kişi araştırmanın örneklemini oluşturmuştur.

Araştırmada veri toplama aracı olarak araştırmacılar tarafından hazırlanan ve Kırıkkale Üniversitesi Sosyal ve Beşeri Bilimler Araştırmaları Etik Kurulundan araştırma izni alınan anket kullanılmıştır. Kişisel bilgiler ile ESpora ilişkin soruların yer aldığı anketin Cronbach's Alpha değeri 0,85 olarak bulunmuştur. Betimsel verilerin çözümlenmesinde yüzde (\%), frekans (f) ve aritmetik ortalama $(X)$ analizleri yapılmış; seçeneğe katılma düzeyinin aritmetik ortalaması 1.00-1.79 olduğunda "hiç katılmıyorum"; 1.80-2.59 olduğunda "katılmıyorum"; 2.60-3.39 olduğunda "kısmen/orta katıliyorum"; 3.40-4.19 olduğunda "katılıyorum" ve 4.20-5.00 olduğunda "çok katılıyorum" olarak yorumlanması kabul edilmiştir.

Shapiro-Wilk testi sonucu, verilerin çarpıklık ve basıklık değerleri -1.5 ile +1.5 aralığında olduğundan, verilerin normal dağılım gösterdiği kabul edilerek (Tabachnick ve Fidell, 2013) iki ayrı kümenin verdiği cevapların analizinde t-testi, çoklu grup karşılaştırmalarında Anova (tek yönlü varyans analizi) testi kullanılmıştır. Anova testlerinde farklılık yaratan grupları belirlemek için çoklu karşılaştırma testi olarak Tukey HSD; sonuç alınamaması durumunda LSD Testi kullanılmıştır. Yapılan yorumlarda anlamlılık düzeyi (p) $<0.05$ olarak belirlenmiştir.

\section{Bulgular}

Araştırmaya katılan akademisyenlerin kişisel bilgileri Tablo 1'de verilmiştir. 
Tablo 1. Kişisel bilgiler

\begin{tabular}{|c|c|c|c|c|}
\hline & & $\mathrm{f}$ & $\%$ & $\mathbf{N}$ \\
\hline \multirow{7}{*}{ Üniversiteler } & İç Anadolu Bölgesi & 76 & 32 & \multirow{7}{*}{241} \\
\hline & Karadeniz Bölgesi & 50 & 21 & \\
\hline & Marmara Bölgesi & 32 & 13 & \\
\hline & Akdeniz Bölgesi & 25 & 10 & \\
\hline & Doğu Anadolu Bölgesi & 25 & 10 & \\
\hline & Ege Bölgesi & 21 & 8,7 & \\
\hline & Güney Doğu Anadolu Bl. & 12 & 5 & \\
\hline \multirow{2}{*}{ Cinsiyet } & Kadın & 54 & 22,4 & \multirow{2}{*}{241} \\
\hline & Erkek & 187 & 77,6 & \\
\hline \multirow{5}{*}{ Yaş } & 25 ve Altı & 10 & 4,1 & \multirow{5}{*}{241} \\
\hline & $26-34$ & 95 & 39,4 & \\
\hline & $35-44$ & 81 & 33,6 & \\
\hline & $45-54$ & 42 & 17,4 & \\
\hline & 55 ve Üstü & 13 & 5,4 & \\
\hline \multirow{4}{*}{ Görev Yaptıkları Bölüm } & BES Öğretmenliği & 103 & 42,7 & \multirow{4}{*}{241} \\
\hline & Spor Yöneticiliği & 73 & 30,3 & \\
\hline & Antrenörlük Eğitimi & 49 & 20,3 & \\
\hline & Rekreasyon & 16 & 6,6 & \\
\hline \multirow{5}{*}{ Akademik Unvan } & Araştırma Görevlisi & 79 & 32,8 & \multirow{5}{*}{241} \\
\hline & Öğretim Görevlisi & 50 & 20,7 & \\
\hline & Dr. Öğretim Üyesi & 56 & 23,2 & \\
\hline & Doçent & 47 & 19,5 & \\
\hline & Profesör & 9 & 3,7 & \\
\hline \multirow{2}{*}{$\begin{array}{l}\text { Elektronik Oyun Oynama } \\
\text { Durumu }\end{array}$} & Evet-Oynarım & 107 & 44,4 & \multirow{2}{*}{241} \\
\hline & Hayır-Oynamam & 134 & 55,6 & \\
\hline \multirow{2}{*}{$\begin{array}{l}\text { Lisanslı Olarak Spor Yapma } \\
\text { Durumlanı }\end{array}$} & Evet & 216 & 89,6 & \multirow{2}{*}{241} \\
\hline & Hayır & 25 & 10,4 & \\
\hline \multirow{5}{*}{ Spor Yapma Sıklıkları } & Her gün & 10 & 4,1 & \multirow{5}{*}{241} \\
\hline & Haftada birkaç kez & 120 & 49,8 & \\
\hline & Ayda birkaç kez & 87 & 36,1 & \\
\hline & Yılda birkaç kez & 11 & 4,6 & \\
\hline & Hiç spor yapmiyorum & 13 & 5,4 & \\
\hline
\end{tabular}

Görüldüğü üzere araştırma katılımclarının çoğunluğu; İç Anadolu (\%32) ve Karadeniz (\%21) Bölgesinde yer alan üniversitelerde görev yapan, erkek $(\% 77,6)$ ve $26-44$ yaş $(\% 73)$ aralığında olan akademisyenlerdir. $\% 42,7^{\prime}$ si Beden Eğitimi ve Spor Öğretmenliği, \%30,3'ü Spor Yöneticiliği bölümünde ve \%32,8'i Araştırma Görevlisi, \%23,2'si Dr. Öğretim Üyesi olarak görev yapmaktadır. Yarısından fazlası dijital oyun oynamadığını $(\% 55,6)$ belirtirken; büyük çoğunluğunun lisanslı olarak spor geçmişlerinin 
olduğu $(\% 89,6)$ ve yaklaşık \%54'ünün haftada birkaç kez ya da her gün spor yaptığı görülmüş̧tür.

Araştırmaya katılan Spor Bilimleri akademisyenlerinin E-Spor ile ilgili görüşlerine ilişkin bilgiler Tablo 2' de verilmiştir.

Tablo 2. Spor Bilimleri akademisyenlerinin E-Spor ile ilgili görüşleri

\begin{tabular}{lll}
\hline Maddeler & X & ss \\
\hline E-Spor bireyleri bilgisayar başına kilitleyerek hareketsiz yaşamı tetikler. & 4 & 0,9 \\
E-Spor fiziksel olarak sağlıklı yaşamdan uzaklaştııır. & 4 & 1 \\
E-Spor sanal ortamda çokça vakit harcanmasından, katılımcıları gerçek dünyadan & 3,8 & 1 \\
uzaklaştııır. & & \\
E-Spor sermaye piyasasının ürünüdür. & 3,8 & 0,9 \\
E-Spor yüz yüze bağlantı gerektirmediğinden, asosyalliği artırır. & 3,7 & 1,1 \\
E-Spor, sporun doğasına ve mantığına aykıııdır. & 3,6 & 1,1 \\
E-Spor bireyleri yalnızlaştırır. & 3,5 & 1,1 \\
E-Sporun, şiddet ve korku içermesinden dolayı olumsuz etkileri vardır. & 3,5 & 1 \\
E-Spor popüler kültürün dayatmasıdır. & 3,5 & 1,1 \\
E-Sporun yaygınlaşması kaçınılmazdır. & 3,5 & 0,9 \\
E-Spor bireyleri yaşadığı topluma yabancılaştırır. & 3,4 & 1,1 \\
Bilgisayar oyunları, dijital oyunlar ve E-Spor oyunları aynı şeydir. & 3,3 & 1,1 \\
E-Spor oyunların içeriğindeki unsurlar nedeniyle şiddeti destekler. & 3,3 & 1 \\
E-Spor para kazanmaya araclık eder. & 3,2 & 1 \\
E-Sporun yaygınlaşmasınn, gerçek sporların yaygınlaşmasına olumsuz etki edeceğine & 3,2 & 1,2 \\
inanıyorum. & & \\
E-Spor oyunları içeriğindeki unsurlar nedeniyle, kültürel yozlaşma yaratabilir. & 3,1 & 1,1 \\
E-Sporun yaygınlaşması desteklenmelidir. & 2,6 & 1,1 \\
E- E-Sporun olimpiyatlarda olması gerektiğine inanıyorum. & 2,0 & 1 \\
\hline
\end{tabular}

Tablo 2'de görüldüğü gibi katılımcılar E-Sporun "sporun doğasına ve mantığına aykırı olduğuna; bireyleri bilgisayar başına kilitleyerek hareketsiz yaşamı tetiklediğine; fiziksel olarak sağlıklı yaşamdan uzaklaştırdığına; bireyleri yalnızlaştırdığına; bireyleri yaşadığı topluma yabancılaştırdığına; oyunların şiddet ve korku içermesinden dolayı olumsuz etkileri olduğuna; yüz yüze bağlantı gerektirmediğinden asosyalliği artırdığına; sanal ortamda çokça vakit harcanmasından dolayı katılımcıları gerçek dünyadan uzaklaştırdığına; para kazanmaya aracılık ettiğine; bilgisayar oyunları, dijital oyunlar ve E-Spor oyunlarının aynı şey olduğuna; yaygınlaşmasının, gerçek sporların yaygınlaşmasına olumsuz etki edeceğine; içeriğindeki unsurlar nedeniyle şiddeti desteklediğine; içeriğindeki unsurlar nedeniyle, kültürel yozlaşma yaratabileceğine; popüler kültürün dayatması olduğuna; sermaye 
piyasasının ürünü olduğuna ve yaygınlaşmasının kaçınılmaz olduğuna" katıldıklarını belirtmişlerdir.

Araştırma sonuçlarına göre Spor Bilimleri akademisyenleri "E-Sporun desteklenmesi ve Olimpiyatlarda yer alması" görüşüne katılmamaktadırlar.

Spor Bilimleri akademisyenlerinin E-Spora yönelik görüşlerinin cinsiyete göre dağılımı Tablo 3'de verilmektedir.

Tablo 3. E-Spora yönelik görüşlerin cinsiyete göre dağılımı

\begin{tabular}{llllll}
\hline Anlamlı Fark Bulunan Görüşler & Cinsiyet & $\overline{\mathbf{x}}$ & $\mathbf{s . s}$ & $\mathbf{t}$ & $\mathbf{p}$ \\
\hline E-Spor oyunlarının, şiddet ve korku içermesinden & Kadın & 3,87 & 0,84 & 3,24 & $0,02^{*}$ \\
dolayı olumsuz etkileri vardır. & Erkek & 3,42 & 1,08 & & \\
& Erkek & 3,30 & 1,11 & & \\
E-Spor oyunların içeriğindeki unsurlar nedeniyle & Kadın & 3,74 & 1,01 & 4,02 & $0,00^{*}$ \\
şiddeti destekler. & Erkek & 3,11 & 1,00 & & \\
E-Spor popüler kültürün dayatmasıdır. & Kadın & 3,78 & 1,09 & 2,42 & $0,01^{*}$ \\
& Erkek & 3,36 & 1,14 & & \\
\hline
\end{tabular}

${ }^{*} p<0.05$

Tablo 3'de görüldüğü üzere akademisyenlerin "E-Spor oyunlarının, şiddet ve korku içermesinden dolayı olumsuz etkileri vardır; E-Spor oyunların içeriğindeki unsurlar nedeniyle şiddeti destekler; E-Spor popüler kültürün dayatmasıdır" ifadelerine ilişkin görüşleri ile cinsiyet arasında istatistiksel olarak anlamlı bir farklılık bulunmaktadır $(\mathrm{p}<0.05)$. Kadın ve erkek akademisyenlerin görüşlerinin aritmetik ortalamaları arasındaki farklılığı ortaya çıkarmak amacıyla yapılan t-testine göre; kadın katılımcılar E-Spor oyunlarının, şiddet ve korku içermesinden dolayı olumsuz etkileri olduğuna, içeriğindeki unsurlar nedeniyle şiddeti desteklediğine ve popüler kültürün dayatması olduğuna erkek katılımcılardan daha fazla katılmaktadırlar.

Tablo 4'te Spor Bilimleri akademisyenlerinin E-Spora yönelik görüşlerinin yaşa göre dağılımı verilmiştir.

Görüldüğü üzere akademisyenlerin "E-Spor bireyleri yalnızlaştırır; ESpor oyunlarının, şiddet ve korku içermesinden dolayı olumsuz etkileri vardır, E-Spor oyunların içeriğindeki unsurlar nedeniyle şiddeti destekler; E-Spor oyunları içeriğindeki unsurlar nedeniyle, kültürel yozlaşma yaratabilir; E-Sporun yaygınlaşması kaçınılmazdır" ifadesine yönelik görüşlerinin yaş kümelerine göre dağılımı arasında istatistiksel olarak anlamlı bir farklılık bulunmaktadır $(\mathrm{p}<0.05)$.

Anlamlı farklılıkların hangi gruplar arasında olduğunu belirlemek amaciyla yapılan çoklu karşılaştırma testlerine göre; E-Sporun bireyleri yal- 
nızlaştırdığına 55 ve üstü yaş grubundaki öğretim elemanları, 26-34 ve 45-54 yaş arasındaki öğretim elemanlarından; 45-54 yaş aralığında olanlar da 2634 yaş arası olanlar da daha fazla katılmaktadırlar. 55 ve üstü yaş grubundaki öğretim elemanları, E-Sporun şiddet ve korku unsurları içermesinden dolayı olumsuz etkileri olduğuna, 26-44 yaş grubundan; 26-34 yaş grubu da 35-44 yaş arasındaki öğretim elemanlarından daha fazla katılmaktadırlar. 25 ve altı yaş grubundaki öğretim elemanları, E-Spor oyunların içeriğindeki unsurlar nedeniyle şiddeti desteklediğine 26-54 yaş arasındaki öğretim elemanlarından daha fazla katıldıklarını belirtirken; 55 ve üstü yaş grubu 45-54 yaş arasındakilerden, 4554 yaş arası grubun da 2634 arasındaki öğretim elemanlarından daha fazla katıldıkları görülmektedir. 55 ve üzeri akademisyenler, E-Spor oyunlarının içeriğindeki unsurlar nedeniyle, kültürel yozlaşma yarattı̆̆ına, 26-44 yaş arasındaki akademisyenlerden daha fazla katılmaktadırlar. 54 ve altı yaş gurubundaki öğretim elemanları, E-Sporun yaygınlaşmasının kaçınılmaz olduğuna, 55 ve üzeri yaş grubundaki öğretim elemanlarından daha fazla katılmaktadırlar.

Tablo 4. E-Spora yönelik görüşlerin yaşa göre dağılımı

\begin{tabular}{|c|c|c|c|c|c|c|c|c|}
\hline & & \multicolumn{5}{|l|}{ YAŞ } & \multirow[b]{2}{*}{ p } & \multirow[b]{2}{*}{$\begin{array}{l}\text { Anlamli } \\
\text { Fark }\end{array}$} \\
\hline \multicolumn{2}{|c|}{ Anlamlı Fark Bulunan Görüşler } & $\stackrel{\text { in }}{\frac{5}{\pi}}$ & 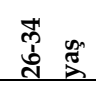 & 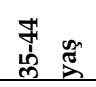 & 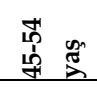 & 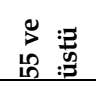 & & \\
\hline \multirow{2}{*}{$\begin{array}{l}\text { E-Spor bireyleri yal- } \\
\text { nızlaştırır. }\end{array}$} & $\bar{x}$ & 3,30 & $3,27^{*}$ & 3,53 & $3,76^{*}$ & $4,08^{*}$ & \multirow[t]{2}{*}{$0,04^{*}$} & $55+>26-$ \\
\hline & ss & 1,49 & 1,32 & 0,93 & 0,85 & 0,64 & & $\begin{array}{l}34 / 45-54 \\
45-54>26-34\end{array}$ \\
\hline \multirow{2}{*}{$\begin{array}{l}\text { E-Spor oyunlarının, şiddet } \\
\text { ve korku içermesinden } \\
\text { dolayı olumsuz etkileri } \\
\text { vardır. }\end{array}$} & $\bar{x}$ & 3,80 & $3,39^{*}$ & $3,38^{*}$ & 3,74 & $4,38^{*}$ & \multirow[t]{2}{*}{$0,00^{*}$} & \\
\hline & ss & 1,13 & 1,10 & 0,93 & 1,03 & 0,65 & & $\begin{array}{l}55+>26- \\
34 / 35-44 \\
26-34>35-44\end{array}$ \\
\hline \multirow{2}{*}{$\begin{array}{l}\text { E-Spor oyunların içeriğin- } \\
\text { deki unsurlar nedeniyle } \\
\text { şiddeti destekler. }\end{array}$} & $\bar{x}$ & $4,00^{*}$ & $3,09^{*}$ & $3,30^{*}$ & $3,17^{*}$ & $3,85^{*}$ & \multirow[t]{2}{*}{$0,01^{*}$} & 25 ve altı \\
\hline & ss & 1,05 & 1,12 & 0,91 & 0,98 & 0,89 & & $\begin{array}{l}>26-54 \\
55+>45- \\
54>26-34\end{array}$ \\
\hline \multirow{2}{*}{$\begin{array}{l}\text { E-Spor oyunları içeriğin- } \\
\text { deki unsurlar nedeniyle, } \\
\text { kültürel yozlaşma yarata- } \\
\text { bilir. }\end{array}$} & $\bar{x}$ & 3,20 & $2,84^{*}$ & $3,16^{*}$ & 3,29 & $4,08^{*}$ & \multirow[t]{2}{*}{$0,00^{*}$} & \\
\hline & ss & 1,13 & 1,17 & 0,98 & 0,97 & 0,86 & & $55+>26-44$ \\
\hline \multirow{2}{*}{$\begin{array}{l}\text { E-Sporun yaygınlaşması } \\
\text { kaçınılmazdır. }\end{array}$} & $\bar{x}$ & $3,70^{*}$ & $3,65^{*}$ & $3,52^{*}$ & $3,62^{*}$ & $2,54^{*}$ & \multirow[t]{2}{*}{$0,00^{*}$} & \multirow{2}{*}{$\begin{array}{l}54 \text { ve altı> } 55 \\
\text { ve üstü }\end{array}$} \\
\hline & ss & 0,67 & 1,00 & 0,85 & 0,79 & 0,96 & & \\
\hline
\end{tabular}


Tablo 5'te Spor Bilimleri akademisyenlerinin E-Spora yönelik görüşlerinin elektronik oyun/bilgisayar oyunu/dijital oyun/ internet oyunları oynama durumuna göre dağılımı verilmiştir.

Tablo 5. E-Spora yönelik görüşlerin elektronik oyun oynama durumuna göre dağılımı

\begin{tabular}{|c|c|c|c|c|c|}
\hline Anlamlı Fark Bulunan Görüşler & $\begin{array}{l}\text { Oynama } \\
\text { Durumu }\end{array}$ & $\bar{x}$ & s.s & $\mathbf{t}$ & $\mathbf{p}$ \\
\hline \multirow[t]{2}{*}{ E-Spor, sporun doğasına ve mantığına aykırıdır. } & Oynarım & 3,31 & 1,20 & - & $0,00^{*}$ \\
\hline & Oynamam & 3,91 & 0,97 & 4,19 & \\
\hline \multirow{2}{*}{$\begin{array}{l}\text { E-Spor bireyleri bilgisayar başına kilitleyerek hareketsiz } \\
\text { yaşamı tetikler. }\end{array}$} & Oynarım & 3,78 & 1,07 & - & $0,00^{*}$ \\
\hline & Oynamam & 4,15 & 0,75 & 3,04 & \\
\hline \multirow[t]{2}{*}{ E-Spor fiziksel olarak sağlıklı yaşamdan uzaklaştırır. } & Oynarım & 3,82 & 1,04 & - & $0,01^{*}$ \\
\hline & Oynamam & 4,14 & 0,87 & 2,58 & \\
\hline \multirow[t]{2}{*}{ E-Spor bireyleri yalnızlaştırır. } & Oynarım & 3,25 & 1,29 & - & $0,00^{*}$ \\
\hline & Oynamam & 3,68 & 0,92 & 2,87 & \\
\hline \multirow[t]{2}{*}{ E-Spor bireyleri yaşadığı topluma yabancılaştırır. } & Oynarım & 3,09 & 1,17 & - & $0,00^{*}$ \\
\hline & Oynamam & 3,72 & 0,88 & 4,61 & \\
\hline \multirow{2}{*}{$\begin{array}{l}\text { E-Spor oyunlarını, şiddet ve korku içermesinden dolayı } \\
\text { olumsuz etkileri vardır. }\end{array}$} & Oynarım & 3,19 & 1,14 & - & $0,00^{x}$ \\
\hline & Oynamam & 3,78 & 0,88 & 4,43 & \\
\hline \multirow{2}{*}{$\begin{array}{l}\text { E-Spor yüz yüze bağlantı gerektirmediğinden, asosyalliği } \\
\text { artırır. }\end{array}$} & Oynarım & 3,40 & 1,22 & - & $0,00^{*}$ \\
\hline & Oynamam & 3,98 & 0,87 & 4,09 & \\
\hline \multirow{2}{*}{$\begin{array}{l}\text { E-Spor sanal ortamda çokça vakit harcanmasından, } \\
\text { katılımcıları gerçek dünyadan uzaklaştırır. }\end{array}$} & Oynarım & 3,48 & 1,13 & - & $0,00^{*}$ \\
\hline & Oynamam & 4,01 & 0,84 & 4,02 & \\
\hline \multirow{2}{*}{$\begin{array}{l}\text { E-Sporun yaygınlaşmasının, gerçek sporların } \\
\text { yaygınlaşmasına olumsuz etki edeceğine inanıyorum. }\end{array}$} & Oynarım & 2,85 & 1,21 & - & $0,00^{*}$ \\
\hline & Oynamam & 3,40 & 1,17 & 3,51 & \\
\hline \multirow[t]{2}{*}{ E-Sporun olimpiyatlarda olması gerektiğine inanıyorum. } & Oynarım & 2,22 & 1,15 & 2,55 & $0,01^{*}$ \\
\hline & Oynamam & 1,89 & 0,89 & & \\
\hline \multirow{2}{*}{$\begin{array}{l}\text { E-Spor oyunların içeriğindeki unsurlar nedeniyle şiddeti } \\
\text { destekler. }\end{array}$} & Oynarım & 3,06 & 1,02 & - & $0,00^{*}$ \\
\hline & Oynamam & 3,41 & 1,02 & 2,67 & \\
\hline \multirow{2}{*}{$\begin{array}{l}\text { E-Spor oyunları içeriğindeki unsurlar nedeniyle, kültürel } \\
\text { yozlaşma yaratabilir. }\end{array}$} & Oynarım & 2,76 & 1,14 & - & $0,00^{*}$ \\
\hline & Oynamam & 3,39 & 0,95 & 4,56 & \\
\hline \multirow[t]{2}{*}{ E-Spor popüler kültürün dayatmasıdır. } & Oynarım & 3,12 & 1,16 & - & $0,00^{*}$ \\
\hline & Oynamam & 3,72 & 1,06 & 4,14 & \\
\hline \multirow[t]{2}{*}{ E-Sporun yaygınlaşması kaçınılmazdır. } & Oynarım & 3,83 & 0,75 & 4,57 & $0,00^{*}$ \\
\hline & Oynamam & 3,31 & 0,99 & & \\
\hline
\end{tabular}

${ }^{*} p<0.05$

Görüldüğü üzere akademisyenlerin "E-Spor, sporun doğasına ve mantığına aykırıdır, E-Spor bireyleri bilgisayar başına kilitleyerek hareketsiz yaşamı tetikler, E-Spor fiziksel olarak sağlıklı yaşamdan uzaklaştırır, E-Spor bireyleri yalnızlaştırır, E-Spor bireyleri yaşadığı topluma yabancılaştırır, ESpor oyunlarının, şiddet ve korku içermesinden dolayı olumsuz etkileri vardır, E-Spor yüz yüze bağlantı gerektirmediğinden, asosyalliği artırır, E- 
Spor sanal ortamda çokça vakit harcanmasından, katılımcıları gerçek dünyadan uzaklaştırır, E-Sporun yaygınlaşmasının, gerçek sporların yaygınlaşmasına olumsuz etki edeceğine inanıyorum, E-Spor oyunların içeriğindeki unsurlar nedeniyle şiddeti destekler, E-Spor oyunları içeriğindeki unsurlar nedeniyle, kültürel yozlaşma yaratabilir, E-Spor popüler kültürün dayatmasıdır" ve "E-Sporun olimpiyatlarda olması gerektiğine inanıyorum, E-Sporun yaygınlaşması kaçınılmazdır" ifadelerine ilişkin görüşleri ile elektronik oyun oynama durumu arasında istatistiksel olarak anlamlı bir farklılık bulunmaktadır $(\mathrm{p}<0.05)$.

Elektronik oyun oynayan ve oynamayan akademisyenlerin görüşlerinin aritmetik ortalamaları arasındaki farklılığı ortaya çıkartmak amacıyla yapılan t-testine göre elektronik oyun oynamayan akademisyenlerin ESporun olumsuz yönlerine yönelik tüm ifadelere, elektronik oyun oynayan akademisyenlerden daha fazla katıldıkları görülürken; "E-Sporun olimpiyatlarda olması gerektiğine ve E-Sporun yaygınlaşmasının kaçınılmaz olduğuna" elektronik oyun oynayan akademisyenler daha fazla katıldıkmaktadırlar.

Tablo 6'da Spor Bilimleri akademisyenlerinin E-Spora yönelik görüşlerinin spor yapma sıklığına göre dağılımı verilmiştir.

Görüldüğü üzere akademisyenlerin "E-Spor bireyleri bilgisayar başına kilitleyerek hareketsiz yaşamı tetikler ve E-Spor para kazanmaya aracılık eder" ifadelerine yönelik görüşlerinin spor yapma sıklığı kümelerine göre dağılımı arasında istatistiksel olarak anlamlı bir farklılık bulunmaktadır $(\mathrm{p}<0.05)$.

Tablo 6. E-Spora yönelik görüşlerin spor yapma sıklığına göre dağılımı

\begin{tabular}{|c|c|c|c|c|c|c|c|c|}
\hline \multirow{2}{*}{\multicolumn{2}{|c|}{ Anlamlı Fark Bulunan Görüşler }} & \multicolumn{5}{|c|}{ Spor Yapma Sıklığg ${ }^{* *}$} & \multirow{4}{*}{$\frac{\mathbf{p}}{0,04^{*}}$} & \multirow{2}{*}{$\begin{array}{l}\text { Anlamlı } \\
\text { Anlamli } \\
\text { Fark }^{* *}\end{array}$} \\
\hline & & 岑 & $\stackrel{v}{\grave{c}}$ & \multirow{2}{*}{$\frac{1}{4}$} & 药 & U & & \\
\hline E-Spor bireyleri bilgisayar & $\bar{x}$ & $3,46^{*}$ & 3,73 & & $4,14^{*}$ & 4,00 & & \\
\hline $\begin{array}{l}\text { başına kilitleyerek ha- } \\
\text { reketsiz yaşamı tetikler. }\end{array}$ & ss & 0,96 & 1,27 & 0,76 & 0,92 & 0,41 & & ABK \\
\hline E-Spor para kazanmaya & $\bar{x}$ & 3,46 & $3,64^{*}$ & $3,29^{*}$ & 3,18 & $2,30^{*}$ & $0,02^{*}$ & YBK-ABK> \\
\hline aracilik eder. & ss & 0,87 & 1,28 & 1,07 & 0,97 & 0,94 & & HG \\
\hline
\end{tabular}

${ }^{*} p<0.05{ }^{* *} Y B K-Y$ ılda birkaç kez, ABK-Ayda birkaç kez, HBK- Haftada birkaç kez, HG- Her gün

Anlamlı farklılıkların hangi gruplar arasında olduğunu belirlemek amaciyla yapılan çoklu karşılaştırma testine göre; Haftada bir kaç kez spor 
yapan öğretim elemanları, E-Sporun bireyleri bilgisayar başına kilitleyerek hareketsiz yaşamı tetiklediğine, hiç spor yapmayan ve ayda bir kaç kez spor yapan öğretim elemanlarından daha fazla katılmaktadır.

Yılda birkaç kez ve ayda bir kaç kez spor yapan öğretim elemanları ise ESporun para kazanmaya aracllı ettiğine, her gün spor yapan öğretim elemanlarından daha fazla katılmaktadırlar.

\section{Tartışma Sonuç ve Öneriler}

Yapılan bu araştırma sonuçlarına göre, Spor Bilimleri alanı akademisyenlerinin E-Spora yönelik görüşleri çok yüksek oranda olumsuzdur ve spor olarak desteklenmesini uygun bulmamaktadırlar. Kadın akademisyenlerin E-Spora yönelik görüşleri özellikle şiddet içerdiğine yönelik ifadelerde, erkek akademisyenlere göre daha olumsuzdur. Daha büyük yaş gruplarında yer alan akademisyenler, kendilerinden genç olan meslektaşlarına göre E-Spora karşı daha yüksek oranda olumsuz görüş bildirmişlerdir. Beden Eğitimi Öğretmenliği bölümünde görev yapan akademisyenlerin genellikle, E-Spora diğer bölümlerde görev yapanlara oranla daha olumsuz baktıkları belirlenmiştir. Elektronik oyun oynamadığını belirten akademisyenlerin ESpora yönelik görüşleri daha olumsuzdur. Akademisyenlerin E-Spora ilişkin görüşleri ile lisanslı olarak spor yapma durumları arasında istatistiksel olarak anlamlı bir fark bulunamazken; spor yapma alışkanlığ bulunan akademisyenlerin olumsuz görüş bildirme düzeylerinin daha yüksek olduğu tespit edilmiştir.

Cinsiyete dayalı görüş ayrılıklarının temel sebebi olarak, erkeklerin kadınlara oranla daha fazla bilgisayar oyunu oynaması (Jeoung ve Kim, 2011; Ko, Yen, Chen C., Chen S. ve Yen, 2005; Mentzoni vd., 2011) ve bu yüzden E-Spor kavramına daha çok aşina olması gösterilebilir. Genellikle ileri yaş gruplarındaki akademisyenlerin E-Spora bakış açılarının daha olumsuz olma nedeni, genç bireylerin teknolojiyle daha fazla ilgilenmesi ve daha fazla teknolojik oyun oynamaları olabilir. Araştırma sonuçlarını destekler nitelikte E-Spor yapan kişilerin çoğunlukla (\%51,7) 15-18 yaş aralığında yer aldığı (Argan vd., 2006, s.6) ve 20-35 yaş aralığında E-Sporun takım sporlarına göre daha popüler olduğu belirlenmiştir (Newzoo, 2017). Beden Eğitimi Öğretmenliği bölümünde görev yapan akademisyenlerin ESpora yönelik görüşleri daha olumsuz olma nedeni ise bu akademisyenlerin 
görev yaptıkları bölüm itibariyle sporu eğitimsel unsurlarla daha fazla bağdaştırmalarından, hatta hedef kitlelerinin çocuklar ve gençler olması nedeniyle E-Sporun zararları konusunda algıda seçicilik yapmalarından kaynaklanıyor olabilir. Araştırma sonuçları beklendiği üzere, dijital oyun oynayan akademisyenlerin E-Spora yönelik görüşlerinin, oynamayanlara göre daha olumlu olduğunu; ayrıca düzenli spor yapan akademisyenlerin E-Spora yönelik görüşlerinin de daha olumsuz olduğunu göstermektedir. Spor yapma alışkanlığı kazanmış bireyin E-Spor ile ilgili olumsuz fikirlere sahip olması doğaldır.

Araştırma sonuçlarına göre, Spor Bilimleri akademisyenlerinin E-Sporun desteklenmesi ve Olimpiyatlarda yer alması görüşüne katılmadıkları görülmektedir. Bulgularla örtüşen bir şekilde IOC Başkanı Thomas Bach da oyunların şiddet ve ayrımcılık içermesinden dolayı Olimpiyat değerleri ile çeliştiğini ve bazı önemli değişiklikler yapılmadan Olimpiyat Oyunlarına bilgisayar oyunlarının dâhil edilmeyeceğini açıklamıştır (Andy, 2018). Benzer şekilde Almanya Kuzey Rhine-Westphalia Spor Federasyonu da ESporu spor olarak kabul etmemektedir. Kurulun açklamış olduğu karar metninde E-Sporun spor olmadığı, modern gençlik kültürünün bir parçası olduğu, spor değerleriyle örtüşmediği ve daha çok ticari bir oluşum olduğu belirtilmektedir (Dijital Sporlar, 2018). Parry (2018) de E-Spor oyunlarının rekabetçi unsurlar içerdiği için spor olarak anılamayacağını ve bilgisayar oyunlarının sadece oyun olduğunu belirtmektedir.

Araştırmadan elde edilen bulgular Spor Bilimleri akademisyenlerinin ESpor ile ilgili görüşlerinin olumsuz olduğu ve E-Sporun oyunculara zarar verebileceğine yönelik görüşleri yüksek oranda benimsediklerini göstermektedir. Birçok araştırma sonucu bu durumu destekler niteliktedir. Nitekim Kraut vd. (1998), internet ve bilgisayar kullanımı arttıkça, bireylerin aileleri ile etkileşiminin azaldığı, sosyal çevrelerinin küçüldüğü, yalnızlık ve depresyon gibi sorunların çoğaldığın belirlemiştir. Bacigalupa (2005) bilgisayar oyunu oynayan çocukları gözlemleyerek yaptığı bir araştırmada, çocukların yaşıtları ile iletişiminin azaldığını veya etkileşim kalitelerinin azalabildiği sonucuna varmıştır. Bununla beraber çocuğun içinde yer aldığı sosyal alanlarda imkân ve risk etkenleri ne olursa olsun şiddet içeren bilgisayar oyunlarının gelecekteki saldırgan davranışlarında artış oluşturabileceği üzerine bulgularda tespit etmiştir. 
Yoğun olarak bilgisayar ve internet kullanımının fiziksel gelişimini tamamlamış yetişkin kişilerde ciddi sağlık sorunları yaratması kadar, fiziksel gelişimini tamamlamamış çocuk ve ergenlerde de çok daha ciddi sağlık sorunları yaratması muhtemeldir. Toronto Üniversitesi'nde sekiz bin kişi üzerinde yapılan bir araştırmada, bireyler bilgisayar ve televizyon başında ne kadar fazla zaman harcarsa, fiziksel aktivitelere katılmaya karşı da bir o kadar isteksiz olmaktadırlar (Koezuka vd., 2006). Yapılan bir çok araştırmada bilgisayar ve internet kullanımının, çocuk ve ergenlerde fiziksel aktivite düşüklüğüne, kilo artışına ve fiziksel anormalliklere neden olduğuna değinilmektedir (Kautiainen, Koivusilta, Lintonen, Virtanen ve Rimpelä, 2005; Mota, Ribeiro, Santos, ve Gomes, 2006).

Yeşilay Bilim Kurulu Üyesi ve Hasan Kalyoncu Üniversitesi Öğretim Üyesi Prof. Dr. Tolga Arıcak yapmış olduğu bir röportajda "Bazı spor bilimciler E-Sporu spor olarak tanımlasa da E-Spor sonuçları ve felsefesi itibariyle spordan elde edilen yararları sağlamamaktadır. İçinde spor kelimesi olması farklı bir şey, gerçek sporlardan elde edilen olumlu sonuçları karşılaması farklı bir şeydir. E-Spor insan sağlığı açısından olumlu sonuçlar yerine riskler barındırmaktadır. E-Spor, Dünya Sağlık Örgütü kriterlerine göre internete ve oyuna olan bağımlılığı artırmaktadır. Bilgisayar oyunlarının büyük bir kısmı şiddet içermektedir. Hareketsiz kalma gibi zararları bir yana, çocuğunuz günde minimum 8-9 saat şiddet içeren oyunlar oynamaktadır. E-Spora olumlu ve olumsuz yönleriyle bakıldığında, bireyler için içerdiği olumsuz etkilerin ve risklerin, olumlu yönlerine göre daha fazla olduğu görülmektedir" şeklinde açıklamalar yapmıştır (Neşeli, 2019).

Teknoloji çağı hayatın her alanına kattığı yeniliklerle bir taraftan yaşamı kolaylaştırırken, diğer yandan sorunlara neden olmuştur. Teknolojinin çıktısı olan hareketsiz yaşam tarzı ve beraberinde getirdiği sorunlar bilim otoriteleri tarafından yıllardır ortaya dökülmektedir. Bu yaşam tarzının en büyük destekçilerinden birisi ise kuşkusuz bilgisayar ve internetin hayatımıza girmesi olmuştur. Bağlamında ortaya çıkan dijital/elektronik oyunların oluşturduğu tehdit giderek büyümekte, bu oyunların getirdiği bağımlılı̆̆ın ve zararlarının ortaya konduğu araştırmalara her gün yenileri eklenmektedir.

Bu durum bilimsel olarak kanıtlanmış olmasına rağmen, bazı ekonomik çevrelerin baskısıyla elektronik oyunlar, sadece içinde rekabet barındırıyor 
olması ve bir miktar fiziksel uğraş gerektirmesine dayandırılarak spor olarak kabul görmektedir. Elektronik oyunların yarattı̆̆ tehlikelerden korunmakta spor önemli bir araç olarak görülürken, elektronik oyunların spor olarak kabul ettirilmeye çalışılması ironik bir durumdur. Bu oyunların, sporun yüzlerce yıldır barındırdığı manevi değerlerin çok uzağında, hatta ve hatta karşısında sonuçlar doğurduğu ortadadır. İki minibus şoförünün yol boyu geliştirdikleri taktiklerle daha fazla yolcu alabilmek için ortaya koyduğu "rekabet", nasıl ki "minibüs sporları"olarak kabul edilemez; ve şöförler de oturduğu yerde gösterdikleri "fiziksel ve düşünsel uğraş" nedeniyle "minibüs sporcusu" olarak isimlendirilemezse; elektonik/dijital oyunlar spor, oyucuları da sporcu olarak nitelendirilmemelidir.

Elektronik oyunların ve aynı nitelikleri taşıyan E-Sporun zararları yadsinamaz. Nitekim E-Spor otoriteleri de bu konuda kendileriyle çelişmektedirler. Türkiye E-Spor Federasyonu kendi yayınladığı 25 Eylül 2019 tarihli 1. E-Spor Çalıştayı sonuç raporunda "E-Sporcuların sağlığı hususunda antrenman, oyun ve beden aktivite sürelerinin belirlenmesi, ek olarak zihinsel yorgunluğu atma ve bedeni rahatlatma programlarmm eklenmesi" konusunda protokoller belirlenmesi yönünde öneride bulunmuştur (ESFED, 2019, s.7). Bu beyanla E-Sporun oyuncularının zihinsel ve bedensel sağlıkların bozduğunu kabul eden E-Spor Federasyonuna, oyuncularının zihinsel yorgunluklarını atma ve bedensel olarak rahatlama programları için diğer "spor" federasyonlarıyla işbirliği yaparak oyuncularına "spor" yaptırması önerilebilir.

Ayrıca yine E-Spor Federasyonu aynı çalıştay raporu sonuçlarında "oyun ve aktivite süreleri dengede tutulursa oyuncu sağllğının korunması"nın mümkün olacağı belirtilmektedir (ESFED, 2019, s.7). Oysa bir spor federasyonu sporcularının sağlığını korumak için kendi branşını bir araç olarak görebilmeli, kendi bünyesinde yer alan uygulamalar nedeniyle sağlığı bozulan oyuncuları için alternatif yollar aramamalıdır. Kaldı ki denetimsiz bir biçimde evde ya da internet kafelerde oynanan bu oyunlara bir süre kısıtlaması getirilemeyeceği ortadadır. Ancak "oyun ve aktivite sürelerini dengede tutarak oyuncuların sağlığını koruyacak, çocuk ve gençleri bilgisayar ve oyun bağımlılı̆̆ından kurtaracak, onları bilgisayar başından kaldıracak en değerli aracın gerçek "spor" olduğu unutulmamalıdır.

Türkiye E-Spor Federasyonu, çalıştayda verileri paylaşılan TÜBİTAK destekli bir çalışmanın ortaya koyduğu “E-Sporun okul hayatını olumsuz 
etkilediğine" yönelik verileri, "gerçeği yansıtmayan bir önyarg" olarak nitelendirmektedir (ESFED, 2019, s.4). E-Spor Federasyonu yetkililerinin, bilim adamlarının onlarca yıldır ortaya koyduğu bilimsel çalışmaları göz ardı etmemesi; TÜBİTAK gibi saygın bir bilimsel kuruluşun verilerini "gerçeği yansıtmayan bir önyargı" olarak göstermeye çalı̧̧mak yerine, ESporun spor olduğunu ve oyuncularına fiziksel ve psikolojik zararları olmadığını ispatlayacak bilimsel çalışma sonuçlarıyla kamuoyunun karşısına çıkması önerilir.

Gençlik ve Spor Bakanlığı, sporun temel taşlarından olan Spor Bilimleri akademisyenlerinin E-Spor ile ilgili görüşlerini dikkate almalı ve spor olgusuyla çelişen "E-Spor" uygulamalarını yeniden değerlendirmelidir.

Spor otoriteleri kitle iletişim araçları yoluyla E-Sporun ne olduğu ve ne olmadığı ile ilgili daha fazla paylaşımda bulunmalıdır.

Kavramin "E-Spor" yerine "elektronik oyun ya da dijital oyun" olarak adlandırılması daha uygun olabilir.

Spor Bilimleri Akademisyenleriyle yapılan bu araştırma spor yöneticilerine, beden eğitimi ve spor öğretmenlerine, antrenör ve sporculara da uygulanarak, spor camiasının konuyla ilgili görüşlerinin ortaya çkarılması sağlanabilir.

Sporun ve fiziksel aktivitenin sağladığı yararlar ve tam zıddı olarak elekronik/dijital oyunların insan ve toplum sağlığına verdiği zararlara yönelik araştırma sonuçlarına rağmen, bu oyunların spor olarak kabul edilmesi ve bu yönde desteklenmesi, bilimsel çalışmaları hiçe saymaktan öteye geçemez. Sporun ortadan kaldırmaya çalıştığı hareketsiz yaşam, yalnızlaşma, yabancılaşma ve birçok psikolojik sorunun oluşumuna aracılık eden bu oyunların spor olarak isimlendirilmesi ve spor kurumlariyla aynı statüde değerlendirilmesi, insanlara faydalı olmak adına yüzyıllardır geliştirilmeye ve yayginlaştırılmaya çalışılan spor kültürüne ve spordan elde edilecek fiziksel, zihinsel, psikolojik ve toplumsal yararlara vurulacak en büyük darbedir.

Elektronik oyunların "spor" olarak sunulmasının, bu oyunlara karşı oluşan antipatinin ve karşı çıkışların önünde koruyucu bir kalkan yaratma çabası olduğu düşünülmektedir. Elektronik oyunların zararları, spor kavramına yüklenen pozitif değerlerin arkasına gizlenmeye çalışılmaktadır. Spor camiasının paydaşları, sporun elektronik oyunların gizli örtüsü olarak kullanılmasının önüne geçmelidir. 
EXTENDED ABSTRACT

\title{
Examining the Perspectives of Sports Science Academics on Electronic Sports
}

\author{
Sibel Arslan- Mehmet Satılmış Bulut \\ Kırıkkale Üniversitesi
}

The fact that E-Sports require competition and physical and mental effort just as is the case with sports constitute the basis for the opinions that electronic games should be deemed as sports. However, E-Sports are not only far from having the quality of providing the physical, mental, psychological and social benefits expected from the real sports, but also incorporate the proven harmful aspects of electronic games.

As people devoted themselves to the dissemination and development of sports, the academicians of the field of sports sciences are the cornerstones of the sports and their opinions in this regard are of importance.

The target population of the study comprises the academicians working in the field of Sports Sciences in Turkey, and the sample of the study comprises 241 academicians. The percentage (\%), frequency (f) and arithmetic mean $(X)$ values were used in the analysis of the descriptive data; the t-test was used in the analysis of the replies given by the two different clusters, the Anova (one-way analysis of variance) test was used in multiple-group comparisons, and the Tukey HDS Multiple-Comparison and the LSD MultipleComparison Tests were used in order to determine the groups making the differences. At the end of the study, it was determined that the opinions of the Sports Sciences academicians concerning the E-Sports were negative, and that they didn't consider them as sport. In addition, it was also determined that there were significant differentiation in their opinions concerning the E-Sports depending on the department they serve in, their age, their status in terms of playing electronic games and their frequency of doing sport.

While sports are considered to be an important instrument for protection against the dangers created by electronic games, it is an irony that it is tried to make the electronic games accepted as sports. It is clear that these games bring about results far from, or even contrary to, the moral values that have been incorporated in sports for many centuries. Just as the "competition" performed by two minibus drivers in order to be able to collect more pas- 
sengers throughout the route by means of the tactics they have developed cannot be considered as "minibus sports" and the drivers cannot be called "minibus athletes" due to the "physical and intellectual effort" they put in while sitting in their seats, the electronic/digital games should not be qualified as sports and the people playing such games should not be called athletes, either.

The harms brought about by electronic games and the E-Sports having the same qualities are undeniable. As a matter of fact, the E-Sports authorities also contradict themselves in this regard. In the final report of the $1^{\text {st }} \mathrm{E}$ Sports Workshop dated September 25, 2019, that was published by itself, The Turkish E-Sports Federation made suggestions concerning the development of protocols for "the determination of the durations of training, game ad bodily activities for the health of e-athletes, and addition of the programs intended for the elimination of mental fatigue and relaxing the body". The E-Sports Federation, which acknowledges with this statement that E-Sports harms the mental and physical health of the people playing them, can be recommended to cooperate with the other "sports" federations concerning the programs intended to eliminate the mental fatigue of the players and ensure their relaxation in order to direct the players to do "sport".

In addition, the E-Sports Federation stated in the final report of the same workshop that it would be possible "to maintain the health of players if a balance is kept between the durations of games and activities" (ESFED, 2019, 7). In fact, a sports federation should be able to see its own branch as an instrument for maintaining the health of its players without needing to seek alternative ways for the players whose health has been harmed due to the activities included within its own body. Moreover, it is evident that no time limitations can be imposed on such games that are played at home or in internet cafes without any inspection. However, it should be remembered that the most valuable instrument that "will protect the health of players by keeping the balance between the durations of games and activities, save children and teenagers from the computer and game addiction and take them away from sitting in front of the computer" is still the "sport".

The data that E-Sports negatively affect the school performance, which was found out by a study supported by TÜBİTAK (the Scientific and Technological Research Council of Turkey) and shared in the workshop, was described by the Turkish E-Sports Federation as "a prejudice not reflecting the truth" (ESFED, 2019, 4). It is recommendable for the officials of the E-Sports 
Federation not to ignore the scientific studies that have been conducted by scientists for decades, and appear before the public with the results of scientific studies proving that E-Sports are sports and they do not inflict physical and psychological harms on players, rather than trying to make the data produced by a reputable institution such as TÜBITTAK appear "a prejudice not reflecting the truth".

The Ministry of Youth and Sport should take the opinions of the Sports Sciences academicians into consideration and reevaluate its practices concerning the "E-Sport" that contradict with the phenomenon of sport.

The sport authorities should share more information, through the media, about what E-Sports are and what they are not.

It may be more suitable for this concept to be named as "electronic games" or "digital games", rather than "E-Sports".

By conducting the present study, which has been conducted on the Sports Sciences academicians, on sports managers, physical education and sports teachers, coaches and athletes, it can be ensured that the opinions of the different circles of sports are brought to light.

Accepting the electronic/digital games as sports in spite of the results of the studies showing the benefits provided by sports and physical activity, or, conversely, the harms the electronic/digital games inflict on the human and public health, and supporting such games in this direction, would be mere disregard of the scientific studies. Calling these games, which contribute to the development of the sedentary lifestyle, isolation, alienation and many psychological problems that sports try to eliminate, as "sports", and considering them at the same status as the sports institutions, is a major blow to the culture of sports that has been tried to be developed and disseminated for centuries in order to produce benefits for people, and to the physical, psychological and social benefits that would be obtained from the sports.

The presentation of the electronic games as "sports" is considered to be an effort to create a protective shield against the antipathy and objection that have developed against such games. The harms brought about by the electronic games are tried to be hidden behind the positive values associated with the concept of sport. The stakeholders of the sports circles should prevent the use of sports as the hiding cover of the electronic games. 


\section{Kaynakça / References}

Akın, E. (2008). Espor: Türkiye'deki esporcular üzerine bir araştırma. Yüksek Lisans Tezi. Anadolu Üniversitesi, Sağlık Bilimleri Enstitüsü, Eskişehir.

Andy, C. (2018). Olympics chief says videogames won't be allowed because they're too violent. 02.07.2019 tarihinde [https://wwww.pcgamer.com/olympics-chief-saysvideogames-wont-be-allowed-because-theyre-too-violent/] adresinden erişildi.

Argan M., Özer A. ve Akın E. (2006). Espor: Türkiye'de Siber sporcuların tutum ve davranışları. Spor Yönetimi ve Bilgi Teknolojileri Dergisi, 1(2), 1306-4371.

Argan M. ve Akın E. (2007). Espor; Özellikleri, kavram ve uygulamalarına yönelik kuramsal çerçeve. Akdeniz 4. Uluslararası Spor Bilimleri Kongresi Bildiri Kitabı, Akdeniz 4. Uluslararası Spor Bilimleri Kongresi, 9-11 Kasım, Antalya.

Bacigalupa, C. (2005). The use of video games by kindergarteners in a family child care setting. Early Childhood Education Journal, 33, 25-30.

Bilgi Teknolojileri ve İetişim Kurumu (2017). Dijital Oyunlar İçin Çocuk ve Aile Rehberliği Çalıştayı Sonuç Raporu. 05.05.2018 tarihinde [http://cocukvebilgiguvenligihaftasi.com/] adresinden erişildi.

Dijital Sporlar (2018). Kuzey Ren-Vestfalya eyalet spor federasyonuna göre Espor bir spor değil. 22.06.2020 tarihinde [https://dijitalsporlar.com/haberler/kuzey-renvestfalya-spor-federasyonuna-gore-espor-bir-spor-degil] adresinden erişildi.

Hamari, J. and Sjöblom, M. (2017). What is eSpors and why do people watch it? Internet Research, 27(2), 211-232.

IESF (2016). IeSF, taking its first step towards IOC recognition. 17.07.2018 tarihinde [https://www.ie-sf.org/news/iesf-taking-its-first-step-towards-iocrecognition/] adresinden erişildi.

IESF (2017). Uluslararast eSpor Federasyonu üye ülkeler. 17.07.2018 tarihinde [http://www.iesf.org/about/\#member-nations] adresinden erişildi.

İnal, A.N. (2000). Beden eğitimi ve spor bilimine giriş. Konya: Desen Ofset Matbaacılık.

Jeong E. J. and Kim D. H. (2011). Social Activities, self-efficacy, game attitudes and game addiction. Cyberpsychology, Behavior and Social Networking, 14(4), 213221.

Jonasson K. and Thiborg J. (2010). Electronic sport and its impact on future sport. Sport in Society, 13(2), 287-299.

Kautiainen S., Koivusilta L., Lintonen T., Virtanen S.M. and Rimpelä A. (2005). Use of information and communication technology and prevalence of overweight and obesity among adolescents. International Journal of Obesity, 29(8), 925-933. 
Kirriemuir J. (2005). Video gaming, education and digital learning technologies. $D$ Lib Magazine, 8(2), 25.

Ko C.H., Yen J.Y., Chen C.C., Chen S.H. and Yen C. F. (2005). Gender differences and related factors affecting online gaming addiction among Taiwanese Adolescents. The Journal of Nervous and Mental Disease, 193(4), 273-277.

Koezuka N., Koo M., Allison K.R., Adlaf E.M., Dwyer J.J., Faulkner G. and Goodman J. (2006). The relationship between sedentary activities and physical inactivity among adolescents: results from the Canadian Community Health Survey. Journal of Adolescent Health, 39(4), 515-522.

Kraut R., Kiesler S., Boneva B., Cummings J. N, Helgeson V. and Crawford A.M. (2002). Internet paradox revisited. Journal of Social Issues, 58, 49-74.

Mentzoni R. A., Brunborg G. S., Molde H., Myrseth H., Skouverøe K. J., Hetland J., vd. (2011). Problematic video game use: Estimated prevalence problematic video game use: Estimated prevalence and associations with mental and physical health. Cyberpsychology, Behavior, and Social Networking, 14(10), 591596.

Mota J., Ribeiro J., Santos M.P. and Gomes H. (2006). Obesity, physical activity, computer use and TV viewing in Portuguese adolescents. Pediatric Exercise Science, 18, 113-121.

Neşeli İ. (2019). E-spor Bağımlllık Riskin Artracak. 02.07.2020 tarihinde [https://yesilay.org.tr/tr/makalelerle-spor-bagimlilik-riskin-artiracak] adresinden erişildi.

Newzoo (2017). 2017 Global games market report - trends, insights and projections toward 2020. 08.05.2018 tarihinde [https://resources.newzoo.com/hubfs/Reports/Newzoo_Global_Games_Market_Report_2017] adresinden erişildi.

Olympic Council of Asia (OCASİA). (2017). OCA, alisports announce e-sports partnership for hangzhou 2022. [http://www.ocasia.org/news/indexnewsrm.aspx?WKegerotea30hootVhTdtQ], Erişim Tarihi: 08.05.2018.

Parry, J. (2018). E-sports are not sports. Sport, Ethics and Philosophy, 13(1) 3-18.

Soysal, E. (2020). Türkiye E-Spor Federasyonu Başkanı Alper Afşin Özdemir'den önemli açklamalar. 03.07.2020 tarihinde [https://wwww.milliyet.com.tr/skorerIturkiye-e-spor-federasyonu-baskani-alper-afsin-ozdemirden-onemli-aciklamalar2701043] adresinden erişilmiştir.

Tabachnick B. and Fidell L. (2013). Using multivariate statistics. 6th international edition. Pearson Education Company, Boston, USA. 
Türkiye Espor Federasyonu (ESFED) (2019). 1. Espor Çalıştayı sonuç raporu. 08.11.2020 tarihinde http://tesfed.gov.tr/PublicFederasyon/Edit/images/FEDERASYON adresinden erişilmiştir.

Uysal A. (2005). Üç boyutlu bilgisayar oyunları tasarımı. Yüksek Lisans Tezi. Anadolu Üniversitesi, Sosyal Bilimler Enstitüsü, Eskişehir.

Yoncacı. M. (2003). Teknoloji ve çağdaş heykel. Yüksek Lisans Tezi. Anadolu Üniversitesi, Sosyal Bilimler Enstitüsü, Eskişehir.

\section{Kaynakça Bilgisi / Citation Information}

Arslan, S. ve Bulut, M. S. (2021). Spor Bilimleri alanı akademisyenlerinin E-Spora bakış açılarının incelenmesi. OPUS-Uluslararası Toplum Araştırmaları Dergisi, 18(41), 3448-3470. DOI: 10.26466/opus.835215. 